Article

\title{
Characterization of Catch-Up Behavior: Accession of Lecture Capture Videos Following Student Absenteeism
}

\author{
Magen Brady ${ }^{1}$, Rachel Wong ${ }^{2}$ and Genevieve Newton ${ }^{2}$ * \\ 1 Department of Biomedical Sciences, University of Guelph, Guelph, ON N1G 3W1, Canada; \\ E-Mail: bradym@uoguelph.ca \\ 2 Department of Human Health \& Nutritional Sciences, University of Guelph, Guelph, \\ ON N1G 3W1, Canada; E-Mail: wongr@uoguelph.ca \\ * Author to whom correspondence should be addressed; E-Mail: newton@uoguelph.ca; \\ Tel.: +1-519-824-4120; Fax: +1-519-763-5902.
}

Received: 19 July 2013; in revised form: 28 August 2013 / Accepted: 4 September 2013 / Published: 11 September 2013

\begin{abstract}
The use of lecture capture in higher education is becoming increasingly widespread, with many instructors now providing digital videos of lecture content that can be used by students as learning resources in a variety of ways, including to catch up on material after a class absence. Despite accumulating research regarding the relationship between lecture capture and attendance, the nature of catch-up behavior following an absence has not been well characterized. This study measured attendance in relation to lecture video accesses to determine whether students catch up after missing a class, and if so, within what timeframe. Overall, it was found that $48 \%$ of absences were not associated with a corresponding lecture video access, and that when absences were caught up, the length of time taken to access the video was highly variable, with the time to the next exam being the likely determinant of when the video was viewed. Time taken to access a video was directly associated with deep learning approach score (as measured by the R-SPQ-2F). Males took significantly longer to view a corresponding lecture video after an absence than females, and missed significantly more classes than females. This study confirms that students use lecture capture variably, and that characteristics such as gender and learning approach influence lecture capture behavior including catch-up following an absence, a finding that is not unexpected given the diversity of students in higher education.
\end{abstract}


Keywords: lecture capture; vodcast; podcast; absenteeism; learning approach; gender

\section{Introduction}

The term "lecture capture" describes the multimedia capturing of live lectures before an audience of students in higher education. While various elements of a lecture (such as instructor audio and video) can be captured, in this study the term 'lecture capture' is used to describe the use of digital technology to capture the instructor's speech and their presentation slides, which were subsequently provided to students in digital video format. The use of lecture capture is becoming increasingly popular in undergraduate and professional education [1,2], with research showing that there has been consistent rise in the use of this technology across a range of institutes of higher education [3]. In fact, Wainhouse Research recently described lecture capture as "one of the hottest campus technologies for higher education", both at present and in the years to come [4].

While there may be technological and pedagogical challenges associated with the use of lecture capture (for a review, see [5]), the associated benefits are significant, and include improved performance [6-9], increased student satisfaction [7,10,11], enhanced understanding of content and clarification of difficult topics [10,12,13], and better access for students with disabilities [7,14] and students for whom English is a second language [15]. These benefits have been the subject of intense research interest over the last several years, as has the association between lecture capture and class attendance, described in detail below. However, despite accumulating research regarding the relationship between lecture capture and attendance, the nature of catch-up behavior following absences from class has not been well characterized. Although it was shown in a study that measured physical attendance that approximately $42 \%$ of students do not catch up by viewing a video after missing a class [16], most studies looking at lecture capture and attendance rely on student self-reports of attendance, or head counts taken at each lecture [17], making it difficult to draw definitive conclusions regarding the use of lecture videos following student absences. Additionally, it remains to be determined whether absences are caught up immediately or after a lapse of time, nor is it known whether catch-up behavior is associated with student characteristics such as gender and student approach to learning.

The relationship between lecture capture and student attendance has been the subject of considerable research attention over the last several years. Several studies suggest that there is only a minimal relationship between these variables, reporting that a majority of students still attend class despite lecture capture videos being available [10,18-23]. Students indicate a variety of reasons for maintaining their attendance patterns, including the need for regular routine, teacher and classmate interaction, and a greater ability to focus with a live presentation [24]. Additional factors that affect lecture attendance are: educational value of the lecture, convenience and flexibility of the timing of the lecture, and social opportunities to exchange ideas and meet new friends [25]. Students report finding face-to-face lectures more valuable than lecture capture videos [26], and that attendance is determined by the qualities of the lecturer, not on the availability of electronic material [27]. However, the finding of a minimal association between lecture capture and attendance is not equivocal; there is also 
evidence that the availability of lecture capture videos online does have a negative impact on classroom attendance [28,29]. While the research investigating the relationship between lecture capture and attendance is expansive, the measurement of attendance in most of these studies was subjective [17].

Research has shown that there are characteristics of students that may be important determinants of how lecture capture is used. Age, or academic level, is one such determinant. Chester et al. [30] found that older students reported using lecture capture more compared to younger students, and it has been found that students in higher academic levels use lecture videos as learning tools, not as opportunities to miss class, in contrast to first year students who use them as a replacement for lectures [28,31]. Gender is another determinant of lecture capture behavior. Females have been found to be more likely to make notes while watching lecture videos and to spend more hours per week doing so than males [21]. Finally, student approach to learning may determine how lecture capture is used. Students with high surface learning approach scores report using recordings more often as a replacement for class, while deep learners report using the videos to review and master material [14]. Cumulatively, research suggests that student characteristics might influence the way students use lecture capture videos, and should be considered in any study that investigates lecture capture behavior.

Regardless of whether the availability of lecture capture has a negative impact on attendance or not, it is well known by instructors in higher education that students regularly miss class. As characterized by Student Affairs at Penn State [32], only half of students report attending all classes, with 5\% reporting missing at least half. Reasons for missing class reported by students include: illness, inconvenience because of timing (for example, it was their only class on campus that day, or was held early in the morning or in the evening), and family situations [22,25,32,33]. Many students feel that lecture capture videos are a valuable asset because when class must be missed for reasons such as medical, employment, or family obligations, the necessary information is available to them to keep up with the course [13]. When providing lecture capture videos to students as resources that can be used to catch up after missing a class, faculty may assume that these resources will be accessed by students, preferably within a short time frame, although it is known that there is considerable variability between students in the way different educational resources (such as lecture videos, associated readings, and the internet) are utilized [16]. However, research has shown that approximately $42 \%$ of student absences are not caught up by accessing the corresponding lecture video [16], although the literature is sparse regarding the frequency of absences that are caught up by accessing the corresponding lecture video in studies measuring physical, rather than self-reported, attendance. There is also uncertainty regarding the time taken to access a video after missing a class, and whether the time to catch-up is related to student characteristics such as age, gender, and learning approach. Therefore, this study fills an important gap in the literature by measuring physical attendance and comparing absences to accesses of corresponding lecture videos, with additional analysis of catch-up behavior in relation to student characteristics that have been previously associated with use of lecture capture. This study was approved by the Research Ethics Board at the University of Guelph. 


\section{Experimental Section}

\subsection{Subjects}

Subjects were enrolled in a second year undergraduate biochemistry course at the University of Guelph in Winter 2012 and Fall 2012. This undergraduate course provides students with the biochemical foundation for the study of human nutrition, exercise, and metabolism. The course covers aspects of biochemistry and metabolism that are critical to understanding human health and fitness. All students in Winter 2012 and Fall 2012 were invited to participate in the study. Student participation in Winter 2012 was $82.3 \%$ (28 out of the 34 total students, mean age $24.41+/-0.8$ years, females $=11$, males = 17 ) and in Fall 2012 participation was 76.5\% (49 out of the 64 total students, mean age $19.75+/-0.14$ years, females $=33$, males $=16$ ). Participating students received a $1 \%$ bonus mark on the final exam. In total, 77 students $(78.6 \%$ of the total students between the two classes) participated in the study.

\subsection{Lecture Capture}

Lectures were captured using the iShowU software for Mac (Shiny White Box, New Zealand) and a Revolabs xTag USB wireless microphone (Revolabs, U.S). Videos were made of the live lecture, capturing both instructor audio and images on the instructor's computer, which primarily showed PowerPoint slides. Links to the videos were provided to students through Courselink, an online learning management system, and were available from 0 (same day) to 2 days after each live lecture. Delays in making lecture capture videos available sometimes occurred due to a lack of technical assistance with converting the digital files to the correct format for hosting on the University server, although this occurred infrequently, with most videos becoming available within 4-24 h. A student username and password were required to access the videos, which were streamed through the University server and were not available for download.

\subsection{Video Accession}

Video access was measured using trackable links in Courselink, the online learning management system. Absences were correlated with video accesses by measuring the time lapse between when the video was posted following an absence (described above as being from 0-2 days after lecture) and the date of the first time that a link was accessed. It should be noted that subsequent link accesses did sometimes occur; this study sought only to determine the time lapse to the first access.

\subsection{Attendance}

The course was offered twice weekly on Tuesday and Thursday mornings, with 24 classes scheduled throughout the semester. The present study only considered attendance on days when lectures were given; after subtracting the dates of the two midterms, and five classes that were dedicated to group projects, a total of seventeen classes were included in the analysis. Attendance at each class for which lecture videos were available was monitored physically by collecting student signatures on a class list that was circulated mid-class. Signature lists were put into sealed envelopes 
after all attendees had the opportunity to sign, and were not viewed by the instructor until after submission of the final course grade. To determine whether absences were caught up by accessing a corresponding lecture capture video, each absence was treated as an independent data point. For the analyses of the length of time to view video, absences that were caught up by accessing the lecture video that corresponded to the missed lecture were similarly treated as independent data points and were grouped into the following categories: 1-7 days, 8-15 days, 16-25 days, 25 days or more. Numbering of days started from the day on which the lecture capture videos became available, which as previously mentioned, ranged from 0 (same day) to 2 days after the lecture. For the analyses of catch-up probability as related to student characteristics, probability was calculated using the following equation: number of classes caught up divided by total number of absences.

\subsection{Revised Student Process Questionnaire 2-Factor}

Student learning approach is commonly measured by the Revised Study Process Questionnaire 2-Factor (R-SPQ-2F) [34], a modified version of the Student Process Questionnaire (SPQ) [35], that was validated as a research tool with which to measure learning approach using the deep and surface scales [36]. All students that participated in the study $(n=77)$ completed the R-SPQ-2F at the end of the semester.

\subsection{Academic Performance}

Final course marks were used as an indicator of academic performance.

\subsection{Statistical Analysis}

Linear regression was conducted to determine the relationships between: (i) probability of catching up by accessing a lecture capture video and learning approach, age, and academic performance, (ii) the length of time to catch up (as divided into the previously described categories) and learning approach, age, and academic performance, (iv) learning approach and performance, and (v) learning approach and the number of classes missed. The Pearson correlation coefficient (r) was calculated for each association. The $r$ value is considered to be the preferred index in a correlational design ([37] Durlak, 2009), with $r$ being widely used to represent effect size in terms of the magnitude and direction of the relationship between the variables ([38] Rosnow, Rosenthal, and Rubin, 2000). The $\mathrm{R}^{2}$ values and the unstandardized co-efficients for the y-intercept and learning approach score were also calculated. Chi-squared tests were conducted to investigate the relationships between gender and the length of time to catch up (as divided into the previously described categories). Effect size for the chi-squared analysis was determined by calculating the Phi coefficient. Unpaired, two-tailed t-tests were conducted to investigate the relationships between: (i) gender and the probability of whether absences were caught up (groups as yes or no), (ii) gender and the number of days (numerical, not categorical) taken to access a video after an absence, and (iii) gender and the number of total classes missed. Significance was indicated at a p-value of less than 0.05 , and a trend was indicated by a p-value between 0.05 and 0.1. All analysis was done with SPSS version 20. 


\section{Results and Discussion}

\subsection{Results}

Catch up behavior was measured by tracking student attendance and subsequent accesses of links to video files in Courselink, the course management software. It was found that $48.4 \%$ of absences were not caught up by accessing the video that corresponded to the missed lecture. For absences that were caught up, these were divided into the categories previously described (Figure 1).

Figure 1. Catch-up behavior for each measured absence. This figure shows that $48.4 \%$ of absences were not caught up by accessing the video that corresponded to the missed lecture, while $11.5 \%$ of absences were caught up within 1-7 days of the video becoming available, $11.5 \%$ were caught up within 8-15 days, $10.2 \%$ were caught up within 16-25 days, and $18.2 \%$ were caught up after more than 25 days.

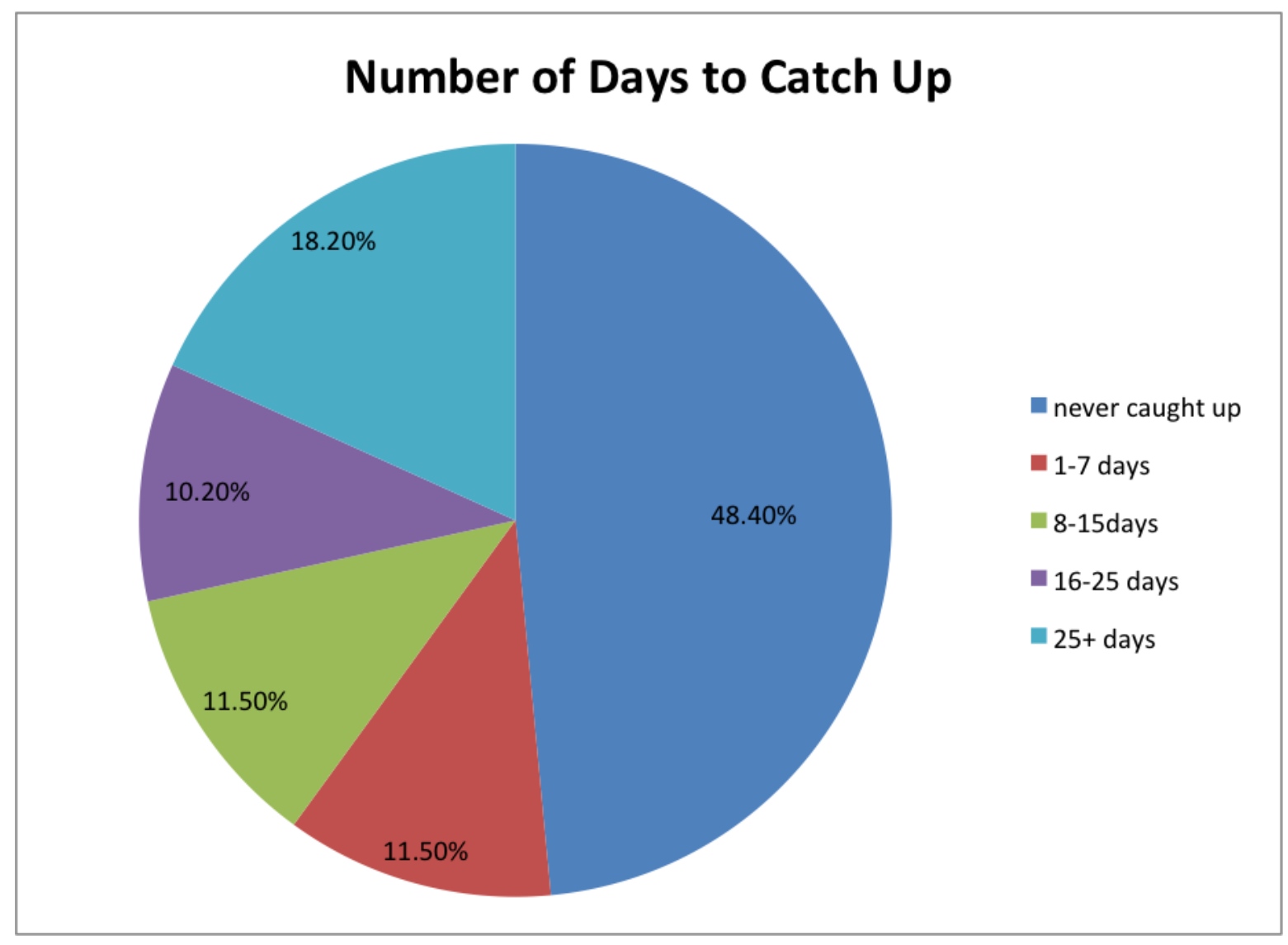

When measuring the relationships between the length of time to catch up and student characteristics, it was found that there was a significant relationship between deep approach score and the categories of number of days to catch up as measured by linear regression. A higher deep approach score was directly related to the category number of days to catch up by watching a video after missing a class $\left(r=0.24, p=0.015, \mathrm{R}^{2}=0.057\right.$ ) as represented by the equation [y (category of number of days to catch up) $=2.439+0.42$ (deep learning approach score), Figure 2]. There were no significant differences between males and females in the categorical analysis of days to catch up ( $p=0.08$, Phi $=0.03$, Figure 3). However, there was a significant $(p=0.015)$ difference in the numerical 
analysis, with males taking longer to catch up than females (males: mean $25.35+/-2.23$ days, females: mean $16.03+/-2.26$ days) as measured by unpaired two-tailed t-test. There were no significant associations between the length of time to catch up and student age or performance.

Males missed significantly $(p=0.003$ ) more classes than females (males: mean $4.42+/-0.77$, or approximately $26 \%$ of classes; female: $1.91+/-0.38$, or approximately $11 \%$ of classes). There were no significant associations between either surface or deep approach score and the total number of classes missed.

Figure 2. Box and whisker plot showing the relationships between deep learning approach score (as measured by the R-SPQ-2F) and the length of time taken to access videos after an absence. There was a significant direct relationship between the variables $(r=0.24$, $p=0.015)$ as determined by linear regression. The line in the box represents the median while the top and bottom of the box represent the $75^{\text {th }}$ percentile and $25^{\text {th }}$ percentile respectively. The ends of the whiskers represent the minimum and maximum of the data.

\section{Number of days to catch up by watching a video after a missing class related to deep learning approach score}

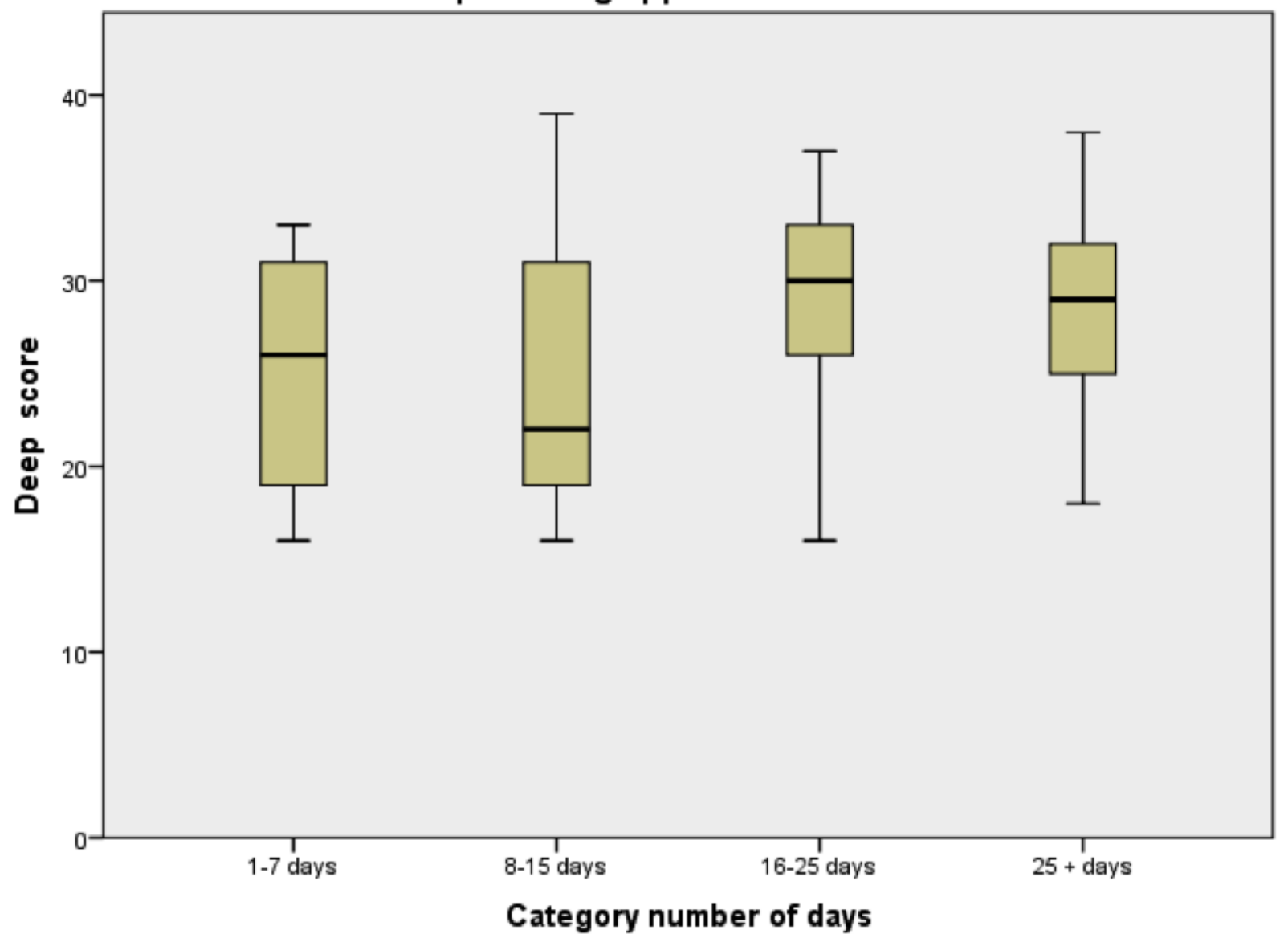

Figure 3. Bar graph showing the length of time taken to access videos after an absence as a function of gender. There was a non-significant $(p=0.08)$ difference between males and females, with males taking longer to catch up than females (males: mean $25.35+/-2.23$ 
days, females: mean16.03 +/- 2.26 days). Percentages reflect the total number of absences that were caught up.

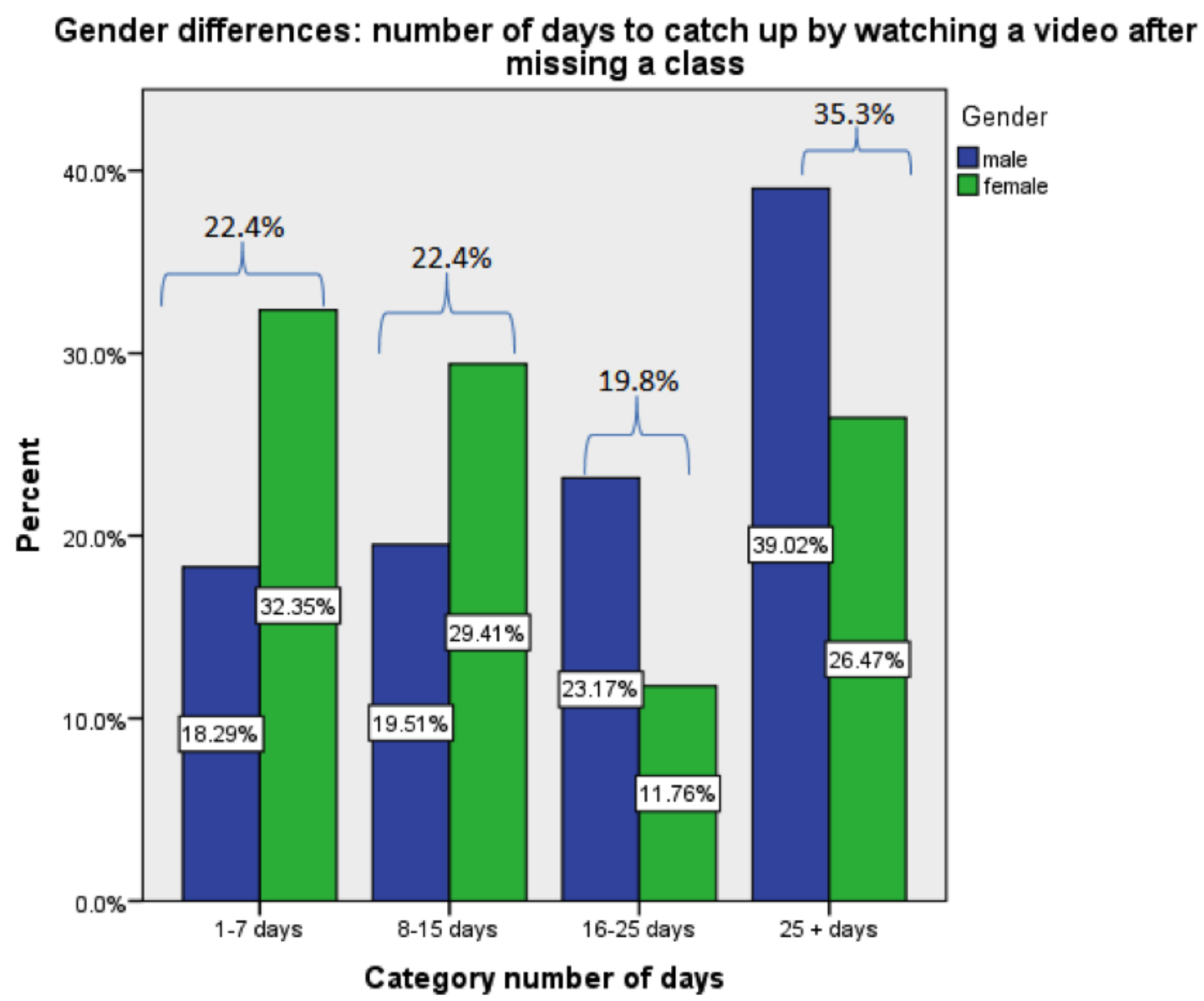

The probability of catching up was determined for each student by taking the total number of absences that were caught up, and dividing this by the total number of absences plus the total number of absences that were caught up. There were no significant differences $(p=0.066)$ between the probability of catching up and gender as measured by unpaired two-tailed t test (Figure 4). There were no significant relationships between the probability of catching up and learning approach, age, and academic performance. 
Figure 4. Gender and probability of catching up from a missed class by watching a video. Error bars represent + /- SEM. $p=0.066$.

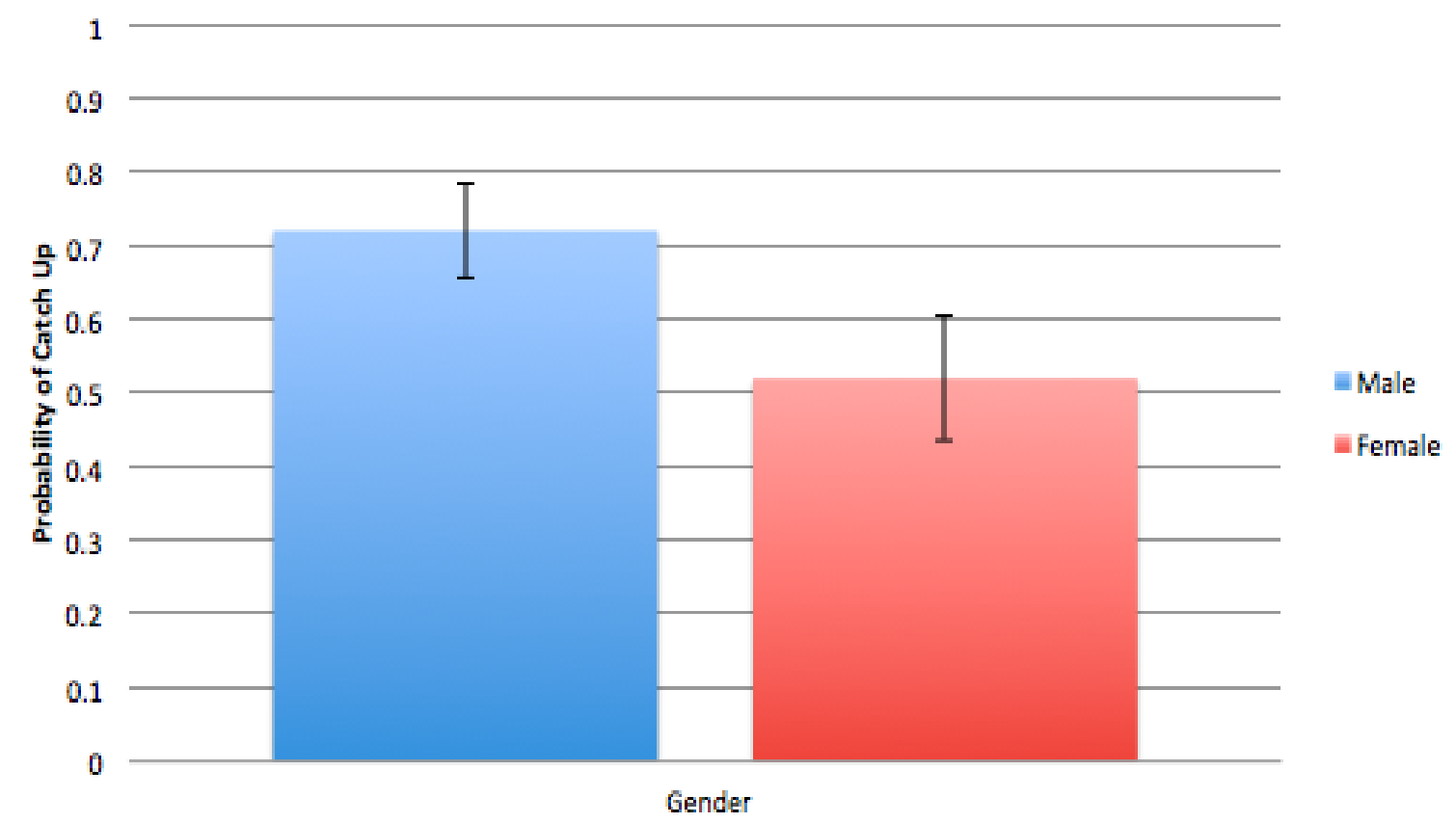

The pattern of video accesses across time for the Fall 2012 class, as well as the dates of the midterms and final exam, illustrate that the peaks of accesses parallel the dates of the examinations (Figure 5). It should be noted that this figure shows data from all students that accessed videos, not only those who were absent. It is known that many students "double up" by both attending class and listening to the recordings $[16,25]$. In this study, when we calculated the ratio of the total number of video accesses per student as compared to the number of catch up video accesses for students who caught up at least one absence, the mean value was 9.4, indicating a high rate of "doubling up".

Figure 5. This figure shows the total number of videos viewed across the Fall 2012 semester. Examinations were held on 2 October 2012, 1 November 2012, and 8 December 2012.

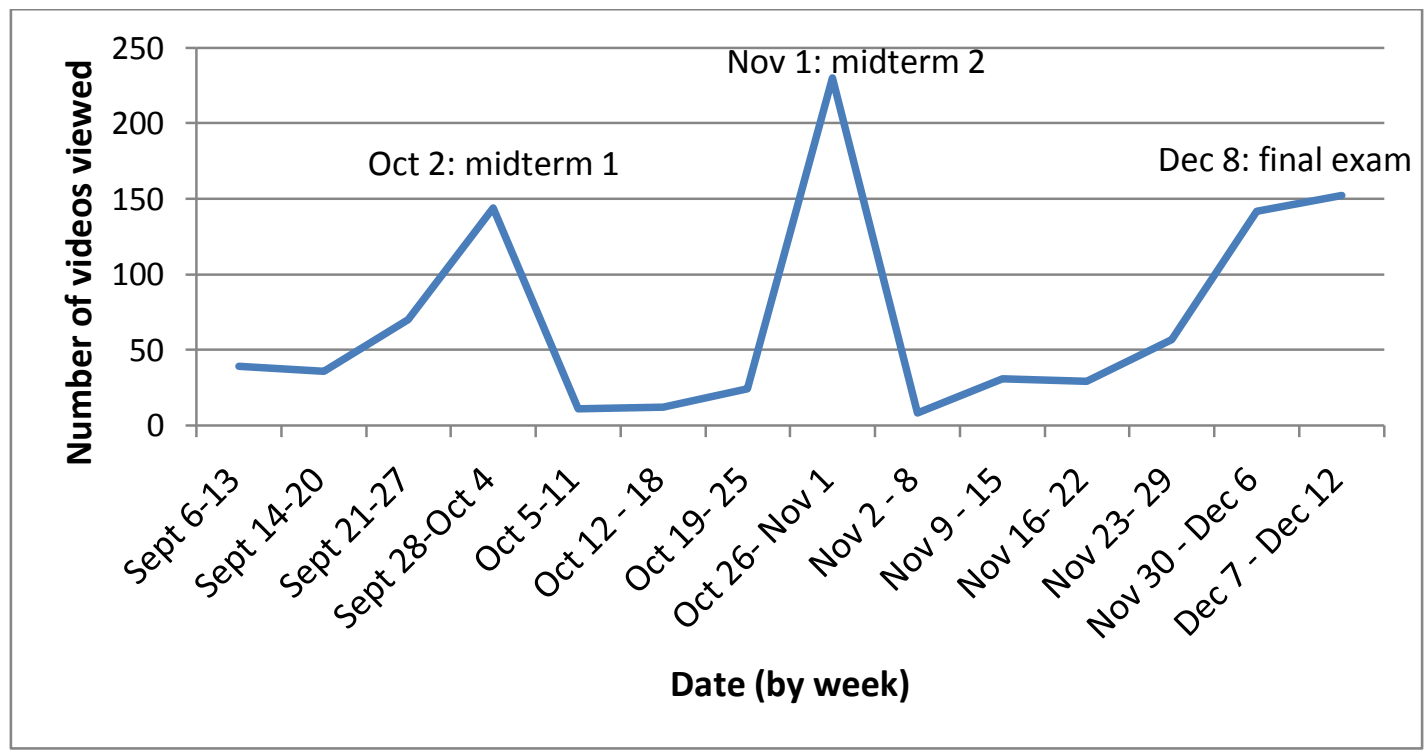


Academic performance was significantly associated with deep learning approach score $(p=0.006$, $\left.r=0.318, \mathrm{R}^{2}=0.101\right)$. There were no significant relationships between academic performance and surface approach score, gender, or age.

\subsection{Discussion}

Although considerable research has investigated the relationship between lecture capture and attendance, whether students that miss a class actually catch-up by accessing the lecture video for the missed class, and the timeframe within which catch-up occurs, has not been well characterized. The objective of this study was to explore the catch-up behavior of undergraduate science students, and to determine whether behavior was influenced by student characteristics such as learning approach, age, and gender. To our knowledge, this is the first study to explore physical attendance in relation to the length of time taken to view a lecture video after an absence, and to evaluate the relationships between length of time to catch up and individual student characteristics that have been previously associated with lecture capture behavior.

The main finding of this investigation was that nearly half of student absences were not caught up by accessing the corresponding lecture video. Of course, this finding does not suggest that students do not catch up by some other means, such as borrowing another student's notes or reviewing the slides from the missed lecture. Importantly, we did not find that academic performance was associated with the probability of catching up from an absence by accessing a corresponding lecture video, suggesting that the missed content was, in fact, addressed somehow by absent students. And, it should also be noted that accessing the video-which in this study, meant accessing a link that brought the students to the streaming video server-does not necessarily mean that students actually watched the video, or watched the video in full. However, these results are a strong indicator that students frequently do not access the only resource that will ensure full exposure to the material covered in lecture. Our findings are comparable to those of von Konski et al. [16], who found that when students missed a class, they did not watch the corresponding video $41.6 \%$ of the time, although we observed an even lower frequency of catch up. Goldfarb et al. [39] found that $67 \%$ of students reported not using available recordings, while Larkin [22] found that less than half the students downloaded the recordings and of those who did only $36 \%$ did so when unable to attend lecture, although both of these reports relied on subjective student reports on attendance and use of lecture capture, unlike the objective measurements presented here and in von Konski et al. [16]. Some of the reported reasons for not using lecture capture videos include using other methods to catch up and not having time to listen to the recordings [40]. Although not measured objectively, students in this study frequently complained about being "too busy" to keep up with the demands of their program, so it is possible that time constraints limited accesses of the lecture videos. However, time constraints are likely to be experienced by students across different levels of education and in different disciplines, so the observation that close to half of the measured absences were not caught up by accessing a lecture capture video may generalize beyond this study, although further research is needed to confirm this finding in other contexts.

The other main finding of this investigation was that for the $52 \%$ of absences that were caught up by viewing a corresponding lecture video, the time taken to access the video was highly variable, dispersing between the categories of catch up between 1-7 days, 8-15 days, 16-25 days, and greater 
than 25 days. When looking at the pattern of video accesses in this study, we observed that it peaks in parallel with the dates of each examination. This is consistent with numerous studies that report increased video accesses near the time of exams, and which indicate revision for exams as the primary motivator for using lecture capture videos $[11,16,19,20,25,26,28,30,40,41]$. This observation could be construed as discouraging, since the inclusive nature of the content of many courses means that lectures frequently build on content presented in previous lectures, and fewer than $12 \%$ of absences were caught up by video accesses within a week. However, academic performance was not related to the time taken to catch up by watching a lecture video, which suggests that students in this class were not impaired academically by the time lapse between absence and video access. It is also possible that other means of catching up on missed material were used shortly after missing class with lecture videos used later to review for the tests and exam.

Although not associated with academic performance, the length of time taken to catch up was significantly influenced by student approach to learning. Deep approach score, as measured by the R-SPQ-2F, was directly associated with the time to catch-up; that is, an increase in deep learning approach score was associated with an increase in the length of time taken to catch up by accessing a lecture video. This finding is somewhat surprising, since a deep learning approach is characterized by understanding, elaboration, analysis, and finding meaning from material [42,43]. Following this, it could be expected that students with a higher deep approach score would be more likely to stay on top of the material, rather than leave missed content towards the end. It is possible that students with a higher deep approach score may use other methods to catch up (such as borrowing notes from a friend) near the date of the absence and wait until closer to the final exam to view the video, although alternative catch-up methods were not investigated in this study. Deep learning approach is often associated with better performance [44], which it was in the present study, although performance did not show a significant association with the time taken to catch up by accessing a video. There was no relationship between the probability of catching up and learning approach, so while the length of time taken to catch up was significantly associated with deep learning approach, deep learning approach was not associated with the likelihood of a student catching up after an absence or not. Investigation of the specific methods of catching up following an absence, as well as further investigation of the relationship between deep learning approach score and catch up methods, is warranted.

The length of time taken to catch up was also significantly influenced by gender. Males took an average of 25 days to catch up from a missed class by watching a video, whereas females took an average of 16 days to catch up. The probability of catching up by accessing a lecture video after an absence was also associated with gender, with males being more likely to catch up than females. However, it should be noted that probability was calculated based on absences that were caught up as a function of total absences, and males missed significantly more classes than females. Chester et al. [30] found no relationship between gender and lecture capture use, but their results were based on subjective student reporting and they did not look specifically at student's catch up behavior. Similarly, Pinder-Grover et al. [31] did not find an association between gender and lecture capture use, although they did not look specifically at attendance. Our objective measurement of attendance and lecture capture use provides an indication for a gender effect on catch up behavior.

This study is limited by its small sample size, although the size is what allowed for effective measurement of physical attendance. The combined number of subjects across both classes was 77 , 
which confers reasonable validity to the findings. It is very difficult to measure individual attendance in undergraduate classes, which is why most studies rely on self-reported, rather than actual, attendance. Additionally, there are characteristics of the program of study of the student participants in this study that may have influenced their attendance patterns. The program has several classes with mandatory attendance, which may encourage attendance across other classes as well. Also, the program has a heavy course load, which could constrain time and reduce the likelihood of students catching up from a missed class by accessing a corresponding lecture video. Although students were told that attendance sheets would not be viewed by the instructor until the end of the semester, it is known that attendance is higher in classes where attendance is recorded [32], so the recording of names may have influenced attendance patterns. On the other hand, the classes in this study were scheduled at 9am two days a week, and was the first scheduled class on one of those days. Early morning classes tend to be less well attended than classes later in the day [32]. This study is also limited by the imprecision of the measurement of video access. As already mentioned, accessing a link does not necessarily indicate that a video was viewed, or that it was viewed in entirety. However, the analytics provided by the streaming server did not distinguish between individual users, so the initial link access was the only metric that could be used to correlate participant absences with video viewing. We did not find any relationships between age and catch-up behavior, but since the subjects in the study were all in the same $2^{\text {nd }}$ year course, the age dispersion may not have been sufficiently broad to investigate this relationship. Age was included as a variable in the analysis since the Winter 2012 class included students in a college transfer bridging program, whose mean age was almost 5 years higher than the Fall 2012 class, but these subjects comprised only 36\% of total subjects. Future research should investigate the relationship between age and catch-up behavior using a bigger sample size across different academic levels.

\section{Conclusions}

Lecture capture is becoming increasingly popular in higher education, and the interest in this technology is projected to intensify in the near future. For this reason, it is important that educators characterize how lecture capture is used by students. This study found that a significant proportion of students do not catch up by accessing a lecture video after an absence, and that when they do, the length of time taken to access the video is likely determined by the time to the next exam. Whether the findings of the present study are interpreted negatively is intricately linked to the question of whether providing lecture capture to students results in a decrease in attendance, and to the nature of the relationships between lecture capture, attendance, and performance. If lecture capture does discourage attendance, then the observation that absences are often not caught up by accessing a corresponding lecture video, or are not caught up within a short timeframe, could be construed negatively; a similar impression would be valid if it were found that the probability of catching up, or the length of time taken to catch up, was associated with student performance. However, this interpretation is not necessarily supported by the literature, which mostly shows that attendance only changes minimally in response to provision of lecture capture $[6,10,18,19,21]$, and furthermore, that lecture capture is often associated with improvements in student performance [6-9]. This interpretation is also not supported by the present study, which did not find any associations between academic performance and whether 
absences were caught up or not, or with the time taken to catch up. This study confirms that students use lecture capture variably, and that characteristics such as gender and learning approach influence lecture capture behavior, including catch-up following an absence; a finding that is not unexpected given the diversity of students in higher education.

\section{Acknowledgements}

The authors would like to thank Michelle Edwards at the University of Guelph for her valuable assistance with statistical analysis.

\section{Conflicts of Interest}

The authors declare no conflict of interest.

\section{References}

1. Toppin, I.N. Video lecture capture (VLC) system: A comparison of student versus faculty perceptions. Educ. Inf. Technol. 2011, 16, 383-393.

2. Grabe, M. Voluntary use of online lecture notes: Correlates of note use and note use as an alternative to class attendance. Comput. Educ. 2005, 44, 409-421.

3. Green, K.C. The Campus Computing Project. Available online: http://www.campuscomputing.net/ sites/www.campuscomputing.net/files/Green-CampusComputing2011.pdf (accessed on 27 August 2013).

4. Greenberg, A.D.; Nilssen, A. Wainhouse Research Paper: Lecture Capture Deployment Models. Available online: http://www.wainhouse.com/files/papers/wr-lecture-capture-deploy.pdf (accessed on 27 August 2013).

5. Newton, G.S.; Tucker, T.; Dawson, J.; Currie, E. Use of lecture capture in higher education: Lessons from the trenches. Tech Trends 2013, in press.

6. Bollmeier, S.G.; Wenger, P.J.; Forinash, A.B. Impact of online lecture-capture on student outcomes in a therapeutics course. Am. J. Pharm. Educ. 2010, 74, 127.

7. Vajoczki, S.; Watt, S.; Marquis, N.; Holshausen, K. Podcasts: Are they an effective tool to enhance student learning? A case study from McMaster University, Hamilton Canada. J. Educ. Multimed. Hypermedia 2010, 19, 349-362.

8. Francom, J.; Ryan, T.G.; Kariuki, M. The effects of podcasting on college student achievement and attitude. J. Res. Center Educ. Technol. 2011, 7, 39-53.

9. Harrigan, K. The SPECIAL system: Self-paced education with compressed interactive audio learning. J. Res. Comput. Educ. 1995, 27, 361-370.

10. Bryans Bongey, S.B.; Cizaldo, G.; Kalnbach, L. Explorations in course-casting: Podcasts in higher education. Campus-wide Inf. Syst. 2006, 23, 350-367.

11. Traphagan, T.; Kucsera, J.V.; Kishi, K. Impact of class lecture webcasting on attendance and learning. Educ. Technol. Res. Dev. 2010, 58, 19-37.

12. Luna, G.; Cullen, D. Podcasting as complement to graduate teaching: Does it accommodate adult learning theories? Int. J. Teach. Learn. High. Educ. 2011, 23, 40-47. 
13. Scutter, S.; Stupans, I.; Sawyer, T.; King, S. How do students use podcasts to support learning? Australas. J. Educ. Technol. 2010, 26, 180-191.

14. Vajoczki, S.; Watt, S.; Marquis, N.; Liao, R.; Vine, M. Students approach to learning and their use of lecture capture. J. Educ. Multimed. Hypermedia 2011, 20, 195-214.

15. Shaw, G.P.; Molnar, D. Non-native english language speakers benefit most from the use of lecture capture in medical school. Biochem. Mol. Biol. Educ. 2011, 39, 416-420.

16. von Konsky, B.; Ivins, J.; Gribble, S. Lecture attendance and web based lecture technologies: A comparison of student perceptions and usage patterns. Australas. J. Educ. Technol. 2009, 25, 581-595.

17. Gomis-Porqueras, P.; Meinecke, J.; Rodrigues-Neto, J.A. New Technologies in higher education: Lower attendance and worse learning outcomes? Agenda 2001, 18, 69-83.

18. Brotheron, J.A.; Abowd, G.D. Lessons learned from eClass: Assessing automated capture and access in the classroom. ACM Trans. Comput.-Hum. Interact. 2004, 11, 121-155.

19. McElroy, J.; Blount, J. You, Me and iLecture. In Proceedings of the 23rd Annual Ascilite Conference: Who's Learning? Whose Technology? Sydney, Australia, 3-6 December 2006; Markauskaite, L., Goodyear, P., Reimann, P., Eds.

20. Chang, S. Academic Perceptions of the Use of Lectopia: A University of Melbourne Example. In Proceedings of the Ascilite Conference, ICT: Providing Choices for Learners and Learning, Singapore, 2-5 December 2007.

21. Pham, J. A case study of classroom podcasts in Ohlone Community College. Available online: http://search.proquest.com/docview/744398076 (accessed on 27 August 2013).

22. Larkin, H. "But they won't come to lectures..." the impact of audio recorded lectures on student experience and attendance. Australas. J. Educ. Technol. 2010, 26, 238-249.

23. Le, A.; Joordens, S.; Chrysostomou, S.; Grinnell, R. Online lecture accessibility and its influence on performance in skills -based courses. Comput. Educ. 2010, 55, 313-319.

24. Copley, J. Audio and video podcasts of lectures for campus-based students: Production and evaluation of student use. Innov. Educ. Teach. Int. 2007, 44, 387-399.

25. Gosper, M.; Green, D.; McNeil, M.; Phillips, R.; Preston, G.; Woo, K. The impact of web-based lecture technologies on current and future practices in learning and teaching. Australian Teaching and Learning Council. Available online: https://www.mq.edu.au/ltc/altc/wblt/research/report.html (accessed on 27 August 2013).

26. Davis, S.; Connolly, A.; Linfield, E. Lecture capture: Making the most of face-to-face learning. Eng. Educ. 2009, 4, 4-13.

27. Billings-Gagliardi, S.; Mazor, K.M. Student decisions about lecture attendance: Do electronic course materials matter? J. Assoc. Am. Med. Coll. 2007, 82, S73-S76.

28. Holbrook J.; Dupont, C. Podcasts and attendance - does year in program matter? Biosci. Educ. 2011, 13.

29. Euzent, P.; Martin, T.; Moskal, P.; Moskal, P. Assessing student performance and perceptions in lecture capture vs. face-to-face course delivery. J. Inf. Technol. Educ. 2011, 10, 295-307.

30. Chester, A.; Buntine, A.; Hammond, K.; Atkinson, L. Podcasting in education: Student attitudes, behaviours and self-efficacy. Educ. Technol. Soc. 2011, 14, 236-247. 
31. Pinder-Grover, T.; Green, K.; Mirecki Millunchick, J. The efficacy of screencasts to address the diverse academic needs of students in a large lecture course. Adv. Eng. Educ. 2011, Winter, 1-28.

32. Penn State University. Available online: http://studentaffairs.psu.edu/assessment/pdf/24.pdf (accessed on 27 August 2013).

33. Silverstein, S. The iPod took my seat. Los Angeles Times, pp. 1, 2. Available online: http://articles.latimes.com/2006/jan/17/local/me-noshow17 (accessed on 27 August 2013).

34. Biggs, J.; Kember, D.; Leung, D. The revised two-factor study process questionnaire: R-SPQ-2F. Br. J. Educ. Psychol. 2001, 71, 133-149.

35. Biggs, J.B. Study Process Questionnaire Manual; Australian Council for Educational Research: Melbourne, Australia, 1987.

36. Justicia, F.; Pichardo, M.; Cano, F.; Berben, A.; de la Fuente, J. The revised two-factor study process questionnaire (R-SPQ-2F): Exploratory and confirmatory factor analyses at item level. Eur. J. Psychol. Educ. 2008, 23, 355-372.

37. Durlak, J.A. How to select, calculate, and interpret effect sizes. J. Pediatr. Psychol. 2009, 34, 917-928.

38. Rosnow, R.L.; Rosenthal, R.; Rubin, D.B. Contrasts and correlations in effect size determination. Psychol. Sci. 2000, 11, 446-453.

39. Goldfarb, S.; Herr, J.; Irrer, J.; McKee, S.; McLachlan, M.; Neal, H. Mscribe: Piloting and evaluating an automated college classroom web lecture capture system; a final report on technical accomplishments. Available online: http://www.umich.edu/ mscribe/docs/MScribeFinalReport.pdf (accessed on 27 August 2013).

40. Pearce, K.; Scutter, S. Podcasting of health sciences lectures; benefits for students from a nonenglish speaking background. Australas. J. Educ. Technol. 2010, 26, 1028-1041.

41. Williams, J.; Fardon, M. Recording lectures and the impact on student attendance. ALT-C Research Paper Submission. Available online: http://www.lectopia.com.au/presentations/ altc2007/ALTC2007Williams_attendance.pdf (accessed on 27 August 2013).

42. Heijne-Pennings, M.; Kuks, J.B.M.; Hofman, W.H.A.; Cohen-Schotanus, J. Influence of open-and closed-book tests on medical students' learning approaches. Med. Educ. 2008, 42, 967-974.

43. Baeton, M.; Dochy, F.; Struyven, K. Students' approaches to learning and assessment preferences in a portfolio-based learning environment. Instr. Sci. 2008, 36, 359-374.

44. Hamm, S.; Robertson, I. Preferences for deep-surface learning: A vocational education case study using a multimedia assessment activity. Australas. J. Educ. Technol. 2010, 26, 951-965.

(C) 2013 by the authors; licensee MDPI, Basel, Switzerland. This article is an open access article distributed under the terms and conditions of the Creative Commons Attribution license (http://creativecommons.org/licenses/by/3.0/) 